\title{
Implementation of an Opioid Management Initiative by a State Medicaid Program
}

Maria M. Garcia, MD, MPH; Michael C. Angelini, MA, PharmD, BCPP; Tara Thomas, RPH, MBA, BCPS; Kimberly Lenz, PharmD; and Paul Jeffrey, PharmD

\begin{abstract}
BACKGROUND: The utilization of prescription opioids has increased over the last 2 decades. Associated with this is the misuse of prescription opioids for nonmedical purposes. Medicaid programs have struggled with developing strategies that balance best practice models, appropriate utilization, and reduction in costs associated with the opioid medication class.
\end{abstract}

OBJECTIVE: To examine the impact of a 2-year stepwise initiative to reduce utilization and therapy costs of long-acting opioid analgesics (LAOA) by addressing issues of high dose, daily dose, and preferred therapeutic alternatives.

METHODS: Utilization data from the Massachusetts Medicaid pharmacy program for LAOAs were reviewed and compared for 2 time periods. The calendar year prior to the initiative, 2002, was used as a base year and represents a time period when there were no restrictions in place for members to obtain long-acting opioids. The calendar year 2005 was the comparison year representing a time period after the multiple steps of the initiative had been implemented. A retrospective claims-based analysis was performed to determine the impact of restrictions on LAOAs, defined as brand and generic versions of oxycodone ER, morphine ER, methadone, and fentanyl transdermal system. The primary measure was the percentage of change of unique utilizers, paid claims, and average daily dose for each LAOA following the implementation of the opioid management initiative. Secondary measures included a cost analysis. RESULTS: Compared with 2002, the overall number of LAOA unique utilizers declined 17.8\% $(P<0.0001)$, and the overall number of claims declined by $4.1 \%(P<0.0001)$, while Medicaid pharmacy benefit member enrollment remained relatively stable. Average daily dose declined in methadone and morphine ER and increased in oxycodone ER and fentanyl transdermal system. The 2005 overall cost of LAOAs decreased $8.0 \%$ compared with the overall cost in 2002. The per-memberper-month (PMPM) cost for opioid users in 2002 was \$110.57 (\$120.04 when adjusted to 2005 dollars) compared with $\$ 123.75$ in 2005. In comparison, the overall PMPM for all members in 2002 was $\$ 3.52$ ( $\$ 3.82$ when adjusted to 2005 dollars) compared with \$3.59 in 2005.

CONCLUSIONS: Our study successfully demonstrated that a state Medicaid program initiative can result in a significant overall decrease in opioid class utilization specifically for the targeted, more costly agents. This was achieved via the implementation of a Therapeutic Class Management multidisciplinary workgroup that established a prior authorization process implementing limits on dose, as well as identified preferred less costly agents. It further facilitated the direct opportunity for pharmacy-prescriber collaboration for LAOA medication management.

J Manag Care Pharm. 2014;20(5):447-54

Copyright $\odot 2014$, Academy of Managed Care Pharmacy. All rights reserved.

\section{What is already known about this subject}

- There has been a significant increase in the number of opioid prescriptions filled and, consequently, a growing incidence of morbidity and mortality.

- Prescription drug misuse is a major public health concern and has significant costs associated with it.

- Safe oversight of pain management is difficult due to the inherent subjectivity of diagnosis and monitoring. Additionally, the opiate medication class has shown a dramatic increase in utilization due to misuse and abuse. These factors have resulted in increased emergency department visits and deaths from accidental overdoses.

- Methods to implement evidence-based guidelines and provide safe practices have not been thoroughly researched. The health care system in the United States is challenged with developing management strategies that balance best practice models, appropriate utilization, and reduction of costs associated with the opioid medication class.

\section{What this study adds}

- This study describes strategies implemented by a state Medicaid program in direct response to the need for improved oversight and management of the long-acting opioid medication class.

- This study shows that a multifaceted initiative that includes oversight regarding poly-pharmacy, dosing limits, and duplicate therapy can positively influence such trends in opioid utilization as decreasing overall utilization, decreasing amount used per member, and decreasing cost.

$\mathrm{N}$ early 75 million Americans are affected by pain each year, and opioid analgesics are among the most effective medications for treatment. ${ }^{1}$ During the past 2 decades, there has been a marked increase in the number of opioid prescriptions filled in the United States. ${ }^{2-5}$ This may be due in part to the recognition that, historically, pain has been undertreated. ${ }^{6}$ In 2000, the Joint Commission (formerly known as the Joint Commission on Accreditation of Healthcare Organizations) introduced new pain management standards for medical care by calling for an increase in awareness by clinicians to be more aggressive at assessing and treating pain. ${ }^{7}$ In response to these new standards, physicians, professional 
societies, and the pharmaceutical industry began advocating for increased opioid use in the treatment of pain. ${ }^{7,8}$

National prescription-tracking data show that more than $40 \%$ of opioid prescriptions are written by general or family practitioners, osteopaths, or internists. ${ }^{8}$ Data from the U.S. Drug Enforcement Agency (DEA) and the Drug Abuse Warning Network (DAWN) indicate large increases in medical and nonmedical use of opioid analgesics. Retail reported use of oxycodone has increased $403 \%$ and fentanyl transdermal system 227\% between 1997 and 2002, as reported by the Automation of Reports and Consolidated Orders System (Arcos). ${ }^{9}$

The Office of National Drug Control Policy (ONDCP) reported that from 1997 to 2007, there was a 4-fold increase in the milligram-per-person use of prescription opioids of $402 \%$ from an average of 74 to 369 milligrams (mg). The American Pain Society recognizes there is no defined high dose for morphine; however, a panel consensus has recently agreed that a reasonable definition is $>200$ milligrams per day ( $\mathrm{mg} /$ day) or the equivalent. ${ }^{6,10}$ In addition, the number of opioid prescriptions dispensed by pharmacies from 2000 to 2009 increased by $48 \% .^{11}$

As newer expert guidelines have encouraged the treatment of pain, there has been a subsequent increase in usage of prescribed opiates. This has resulted in a growing concern for potential harm, particularly from abuse and misuse. ${ }^{12,13} \mathrm{~A}$ review of utilization from 1997 to 2005 found that there was a positive correlation between prescribed opioid doses and the risk of overdose events. ${ }^{14}$ From 2004 to 2008, there was more than a 2-fold increase in emergency department visits related to opioid abuse. ${ }^{15,16}$ Furthermore, the Center for Disease Control and Prevention has reported that in 2007, the number of deaths associated with opioid overdoses was more than that of heroin and cocaine combined. ${ }^{17}$ According to the 2010 National Survey on Drug Use and Health (NSDUH), approximately 5.1 million persons of age 12 and older reported the nonmedical use of pain relievers in the month preceding the survey. ${ }^{18}$

There is a considerable cost associated with opioid abuse. It is estimated that the U.S. government spends approximately $\$ 300$ billion per year in costs related to all types of drug abuse. ${ }^{19}$ An analysis of data prior to 2007 estimated that the U.S. societal cost of prescription opioid abuse was $\$ 55.7$ billion in 2009 dollars with workplace costs accounting for $46 \%$, health care costs $45 \%$, and criminal justice costs $9 \%{ }^{20}$ Insurance expenditures (medications, hospitalizations, and physician visits) were over 8 times higher in opioid abusers than in nonabusers. ${ }^{21}$

In April 2011, the ONDCP declared that prescription drug abuse and misuse "is a major public health and safety crisis." ${ }^{2}$ A joint action plan was put in place by the ONDCP, the U.S. Food and Drug Administration, and the DEA calling for initiatives that included the education of health care providers and patients and enhanced monitoring of opioid prescribing. ${ }^{11}$
In Massachusetts, treatment admissions for the abuse of opioids increased nearly 9-fold between 1992 and 2002. ${ }^{23}$ In 2005, opioid analgesics ranked eighth in the top 10 drug classes utilized by the Massachusetts Medicaid Pharmacy program. ${ }^{24}$ Furthermore, according to the 2006 NSDUH, Massachusetts ranked ninth nationally in the misuse of prescription pain relievers by those aged 18 and older. ${ }^{25}$

Published data regarding oversight of opioid medications by state Medicaid pharmacy programs are limited. Effective utilization management strategies for Medicaid programs include the use of a preferred drug list and a prior authorization (PA) process. ${ }^{26-30}$ A 2008 study summarizing the impact of 21 state Medicaid PA processes on oxycodone controlled-release demonstrated that changes in use and expenditures associated with PA implementation varied among states. However, a significant impact was not observed for most states. The authors concluded that, compared with other drugs, oxycodone extended-release (ER) prescribing and dosing appeared relatively unaffected by Medicaid PA requirements. ${ }^{31}$

In direct response to the need for improved oversight and management of this medication class, Massachusetts Medicaid (MassHealth), through the Drug Utilization Review (DUR) program, began reviewing opioid utilization data in October 2002. A multistep strategy via the PA process was established, incorporating clinical approval criteria addressing defined high dose, daily dose, and preferred therapeutic alternatives on long-acting opioid analgesics (LAOA). The multiple steps of this initiative were implemented with changes to the MassHealth Drug List. The list is a nontiered formulary that provides information regarding coverage status of medication. The management strategies also included the creation of a Therapeutic Class Management (TCM) multidisciplinary team. In this article, we describe the process, timeline, implementation strategies, utilization, and economic outcomes of this LAOA initiative implemented by the Massachusetts Medicaid program.

\section{Methods}

\section{Study Design}

This study involved a retrospective claims-based data analysis that examined the impact of newly introduced PA restrictions on the management of selected LAOAs. Utilization data for the LAOAs were reviewed and compared for 2 time periods: the year prior to implementation of the initiative (2002) and the year after initiative implementation (2005). Quantitative measures analyzed included number of unique utilizers and claims, as well as average daily dose captured by the pharmacy claims processing program. Average daily doses for each individual member were calculated by identifying the number of tablets, days' supply, and the dose for every claim filled during the review period. Not all opioids have the same clinical potencies, which may create a problem when attempting to compare dose 


\section{FIGURE 1 Prior Authorization Review Process}

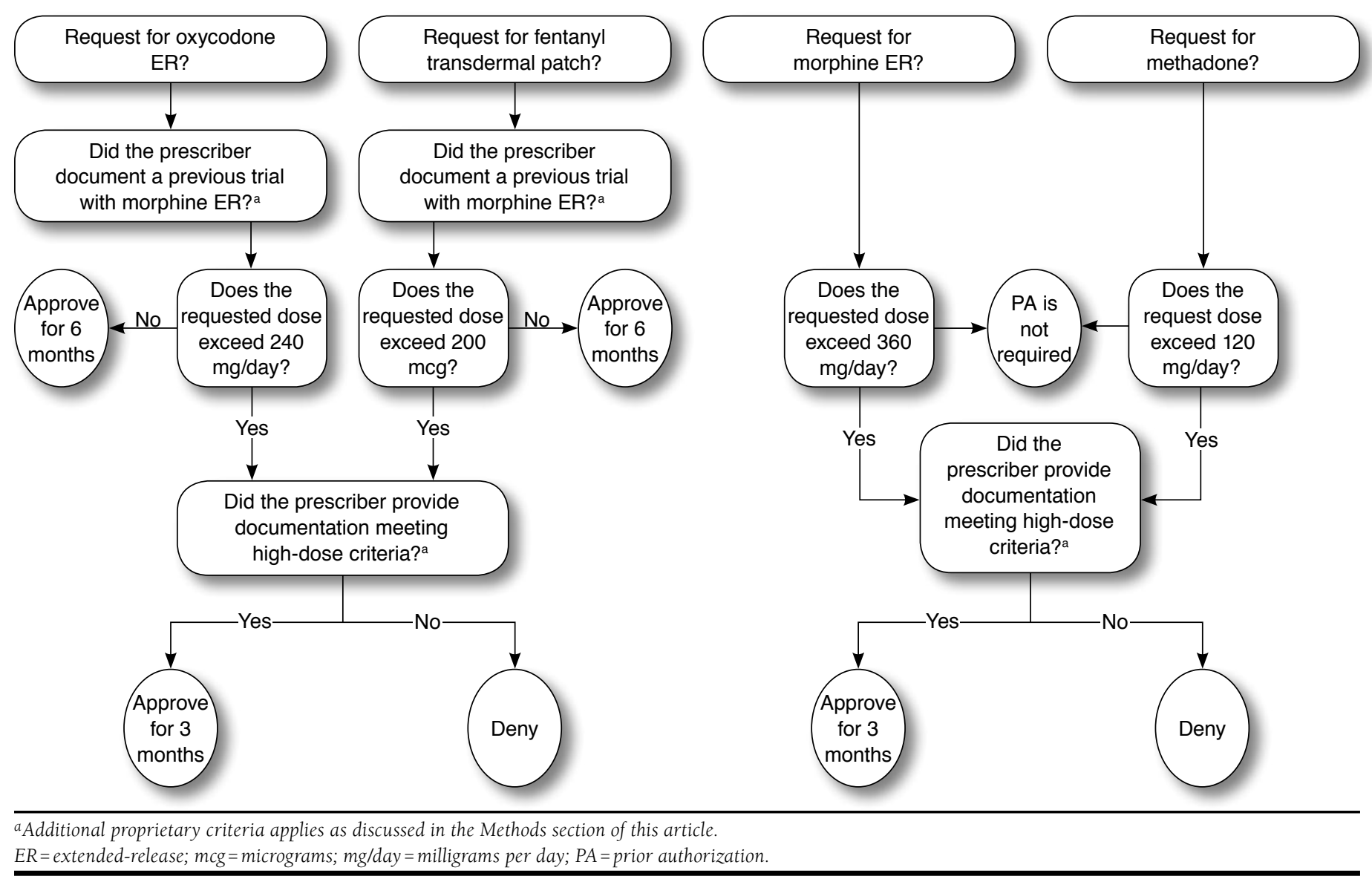

or change in dose between opioids. Therefore, in this study, all doses were converted to oral morphine equivalents (OMEQ). ${ }^{32}$

\section{Participants}

Participants included any MassHealth member enrolled in the Massachusetts Medicaid pharmacy benefit during any time period between January 1, 2002, and December 31, 2005, with claims for oxycodone ER, fentanyl transdermal system, any morphine ER formulation, or methadone. All claims for these agents were included regardless of the members' duration of coverage eligibility, diagnosis, days' supply or dose of medication. MassHealth members receiving methadone through a methadone maintenance program for the purposes of treating opioid addiction are not included in this data, since this therapy may be dispensed only by opioid treatment programs and is not billed for through the pharmacy online processing system.

\section{Interventions}

In 2002, the MassHealth DUR program performed a utilization data review and determined that a management strategy for
LAOAs was warranted. Interventions were implemented via a multiple step process. Initially, PA restrictions on dose limits were implemented for oxycodone ER, fentanyl, morphine ER, and methadone. In order to determine high-dose criteria, dose per day was plotted against number of claims. The data fell into a bell shaped distribution with a long tail towards higher doses. Data in the long tail region of the graph were classified as "outliers" and were excluded from determination of the mean and standard deviation to avoid skewing the results. Doses identified as greater than 2 standard deviations above the mean were identified as high doses. This MassHealth utilization distribution analysis was repeated for all claims for each of the LAOAs for purposes of defining the PA high-dose requirement. Based on this analysis, the following were defined as dose limits; 240 mg per day (mg/day) of oxycodone ER, 200 micrograms per hour $(\mu \mathrm{g} / \mathrm{hr})$ of fentanyl, $360 \mathrm{mg} /$ day of morphine ER, and $120 \mathrm{mg} /$ day of methadone. These doses were specific to the observed utilization trends and not equipotent to each other. All high-dose LAOAs required a PA request for approval based on the defined high-dose criteria. 
Implementation of an Opioid Management Initiative by a State Medicaid Program

TABLE 1 Change in Yearly Utilizers and Claims

\begin{tabular}{|c|c|c|c|c|c|c|}
\hline & 2002 & 2003 & 2004 & 2005 & $\begin{array}{l}\text { Change in } \\
\text { Number }\end{array}$ & $\%$ Change $^{a}$ \\
\hline \multicolumn{7}{|c|}{ Oxycodone extended-release } \\
\hline Unique utilizers & 11,413 & 10,695 & 7,926 & 5,212 & $-6,201$ & -54.3 \\
\hline Number of claims & 85,804 & 80,815 & 72,980 & 55,860 & $-29,944$ & -34.9 \\
\hline \multicolumn{7}{|c|}{ Fentanyl transdermal system } \\
\hline Unique utilizers & 8,059 & 8,873 & 6,530 & 3,982 & $-4,077$ & -50.6 \\
\hline Number of claims & 42,333 & 48,340 & 45,343 & 31,755 & $-10,578$ & -25.0 \\
\hline \multicolumn{7}{|c|}{ Morphine extended-release } \\
\hline Unique utilizers & 2,829 & 3,258 & 4,801 & 6,490 & $+3,661$ & +129.4 \\
\hline Number of claims & 15,385 & 17,336 & 22,944 & 33,450 & $+18,065$ & +117.4 \\
\hline \multicolumn{7}{|l|}{ Methadone } \\
\hline Unique utilizers & 1,852 & 2,323 & 3,126 & 4,171 & $+2,319$ & +125.2 \\
\hline Number of claims & 12,788 & 16,627 & 21,992 & 28,839 & $+16,051$ & +125.5 \\
\hline \multicolumn{7}{|l|}{ All opioids } \\
\hline Total unique utilizers & 24,153 & - & - & 19,855 & $-4,298$ & -17.8 \\
\hline Total number of claims & 156,310 & - & - & 149,904 & $-6,406$ & -4.1 \\
\hline
\end{tabular}

All PAs for high-dose LAOAs submitted to MassHealth DUR are individually reviewed by clinical pharmacists accessing the member's pharmacy utilization database using a pharmacy claims program. All high-dose PA opioid requests require further documentation by prescriber for the (a) medical necessity for high dose (may require office note documentation or medical records); (b) complete pain management treatment plan; (c) previous trials of non-narcotic, narcotic, and nonpharmacological treatments (may require office notes or medical records); (d) signed and dated pain contract; (e) information about any history of early refill, lost, or stolen controlled substances; and (f) pain consult from pain specialist or specialized training in pain management that addresses the high dose. The clinical pharmacist would make a determination of PA approval or denial within 24 hours of request submission and fax the request back to the doctor's office with an outgoing message explaining the rationale for decision (Figure 1).

In April 2004, MassHealth added PA requirement status for oxycodone ER and fentanyl transdermal system so that all "new starts" for these agents would require PA approval. The new starts were defined as a prescription for oxycodone ER or fentanyl transdermal system when there have been no paid claims for the medication in the last 90 days. Requests were also reviewed for trials of less costly alternatives. Morphine ER is considered the preferred less costly alternative on the MassHealth formulary. Members who were noted to have renal or hepatic dysfunction were able to bypass the morphine trial requirement due to the potential of medical risks associated with these conditions. Once a PA was approved, if the member continued to fill the medication in a manner that did not reclassify it as a new start and the dose did not escalate to one determined to be a high dose, there would be no further need for PA submission.
A multidisciplinary TCM workgroup team was also created to enable the implementation of clinical approval criteria and communication with MassHealth prescribers on PA requirements and restrictions. A team consisting of 2 physicians (internal medicine and anesthesiology with pain management specialty), 2 clinical pharmacists, and a behavioral health specialist pharmacist (addiction medicine) met every 2 weeks to discuss identified high-dose utilization regimen profiles. PA requests requiring phone interventions for clarification of PA requirements, treatment care plans, or specific restrictions, including alternative options for less costly alternative equally effective regimens, were facilitated by members of this multidisciplinary workgroup team. The development of the MassHealth PA clinical approval criteria and communication was guided by available evidence-based literature. ${ }^{6,12}$

\section{Outcome Measures}

Primary Outcome Measures: Yearly changes in unique utilizers and the number of claims from the pre-initiative implementation period (2002) to the postinitiative implementation period (2005) were examined to describe the impact of requiring a PA for oxycodone ER, fentanyl transdermal system, morphine ER, and methadone. Average daily dose was also calculated to provide an illustration of the impact of dose limits that were implemented.

Secondary Outcome Measures: A cost analysis was conducted to determine the impact, if any, of the multiple interventions. Total cost for each individual agent, total cumulative costs for all the long-acting agents, average cost per claim, and per-member-per-month (PMPM) metrics were also examined. 


\section{FIGURE 2 Average Daily Dose in Morphine Equivalents}

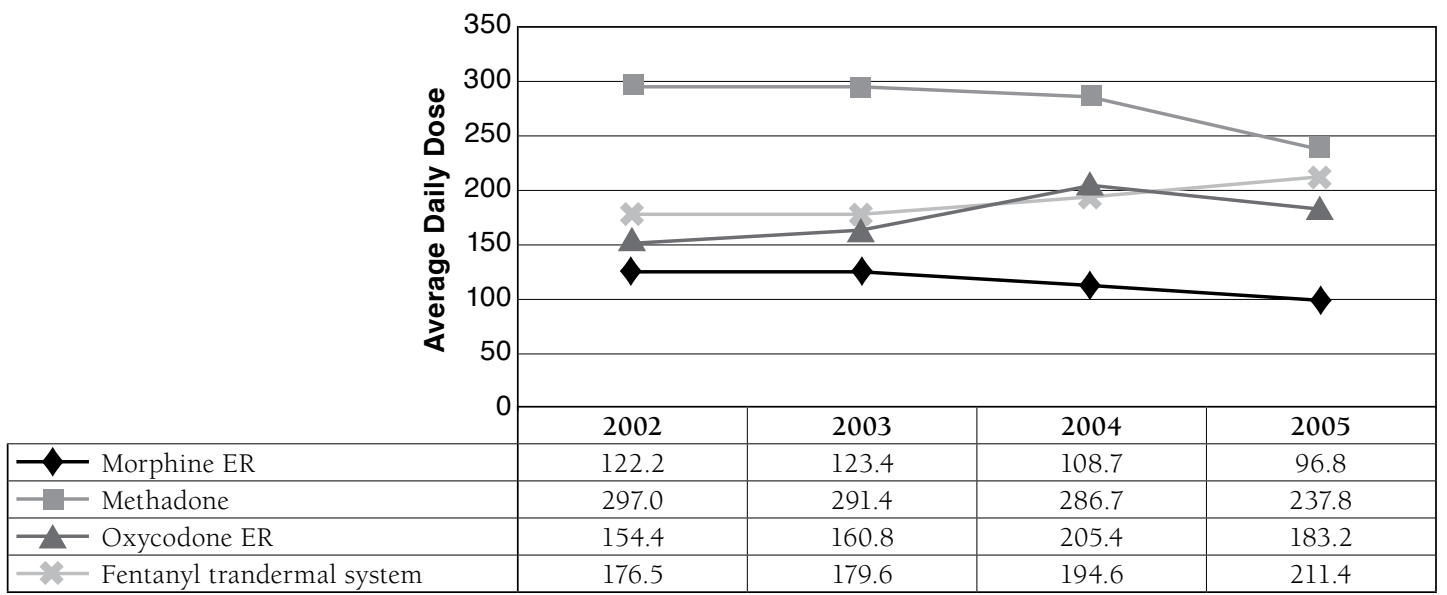

$E R=$ extended-release

\section{Statistical Analyses}

The statistical significance of the change in utilizers and claims between years 2002 and 2005 were determined from the monthly averages within each respective year. The $P$ values were calculated from these monthly averages by using the Student's t-test. A cost analysis on the cumulative impact of all implemented interventions was also performed and reported as change in total cost, as well as the impact on PMPM unit measure yearly costs for both overall and opioid utilizers. Inflation costs were calculated utilizing the CPI Inflation Calculator available at http://data.bls.gov/cgi-bin/cpicalc.pl.

\section{Results}

Over the entire review period, the total pharmacy program enrollment remained relatively stable at approximately 700,000 lives annually. During the study period of 2002 to 2005 , the total number of unique utilizer decreased by $17.8 \%(P<0.0001)$, and the number of claims decreased by $4.1 \%(P<0.0001$; Table 1$)$. There was an overall decrease in oxycodone ER and fentanyl transdermal system for both the number of unique utilizers and number of claims. Specifically, the number of unique utilizers and claims for oxycodone ER decreased by 6,201 (54.3\%) and 29,944 (34.9\%), respectively. For fentanyl transdermal system, unique utilizers decreased by 4,077 (50.6\%), and the claims decreased by 10,578 (25.0\%). Conversely, the utilization of morphine ER and methadone increased. Specifically, unique utilizers and claims for morphine ER increased by 3,661 (129.4\%) and by 18,065 (117.4\%), respectively, and for methadone by 2,319 (125.2\%) and by 16,051 (125.5\%), respectively. The change in the number of unique utilizers and the claims from 2002 to 2005 are illustrated in Table 1.
The average daily doses in OMEQ for years 2002 to 2005 are depicted in Figure 2. Morphine ER and methadone decreased by $20.8 \%$ and $19.9 \%$, respectively. Conversely, there was a steady increase in fentanyl transdermal system doses for a total increase of $20.0 \%$ over the 4 years. Oxycodone ER also experienced an overall increase of $18.7 \%$ in the average daily dose, although the dose in 2005 was in fact lower than that documented in 2004. The average cost per claim was compared for LAOAs. Morphine ER and methadone average cost per claim decreased by $17 \%$ and $24 \%$, respectively, whereas there was an increase for oxycodone ER and fentanyl by $21 \%$ and $32 \%$, respectively (Table 2). The 2005 overall cost of LAOAs decreased $8.0 \%$ compared with the overall cost in 2002 .

The total amount paid for all LAOAs (reimbursement to the pharmacy for the prescription) initially showed an increase in the first 2 years, followed by a decrease in 2005 (Figure 3). Most of the increase was a reflection of the amount paid for fentanyl transdermal system. Oxycodone ER showed a constant decrease, whereas morphine ER showed a steady increase, and methadone remained stable. The overall number of members in 2002 was 757,775 , which decreased to 685,070 in 2005 . The overall PMPM for all members decreased $6.3 \%$, from $\$ 3.82$ to $\$ 3.59$, when costs were adjusted to 2005 dollars. Conversely, when applied to only opioid utilizers, the total number of members using opioids in 2002 was 24,153, which decreased to 19,855 in 2005 . The PMPM for opioid utilizers increased $3.1 \%$, from $\$ 120.04$ to $\$ 123.75$, when costs were adjusted to 2005 dollars. 


\begin{tabular}{|c|c|c|c|c|c|}
\hline & $2002(\$)$ & $2003(\$)$ & $2004(\$)$ & $2005(\$)$ & $\begin{array}{c}\text { Percent Change in Average } \\
\text { Cost Per Claim } \\
\text { Between } 2002 \text { and } 2005(\%)\end{array}$ \\
\hline Morphine ER & 139.30 & 143.76 & 131.00 & 115.21 & -17 \\
\hline Methadone & 21.15 & 20.03 & 18.20 & 16.07 & -24 \\
\hline Oxycodone ER & 237.89 & 259.97 & 278.25 & 286.72 & +21 \\
\hline Fentanyl transdermal system & 217.86 & 244.62 & 289.99 & 288.24 & +32 \\
\hline
\end{tabular}

aTrue dollar amounts as reported for year, not adjusted for inflation.

\section{FIGURE 3 Total Amount Paid}

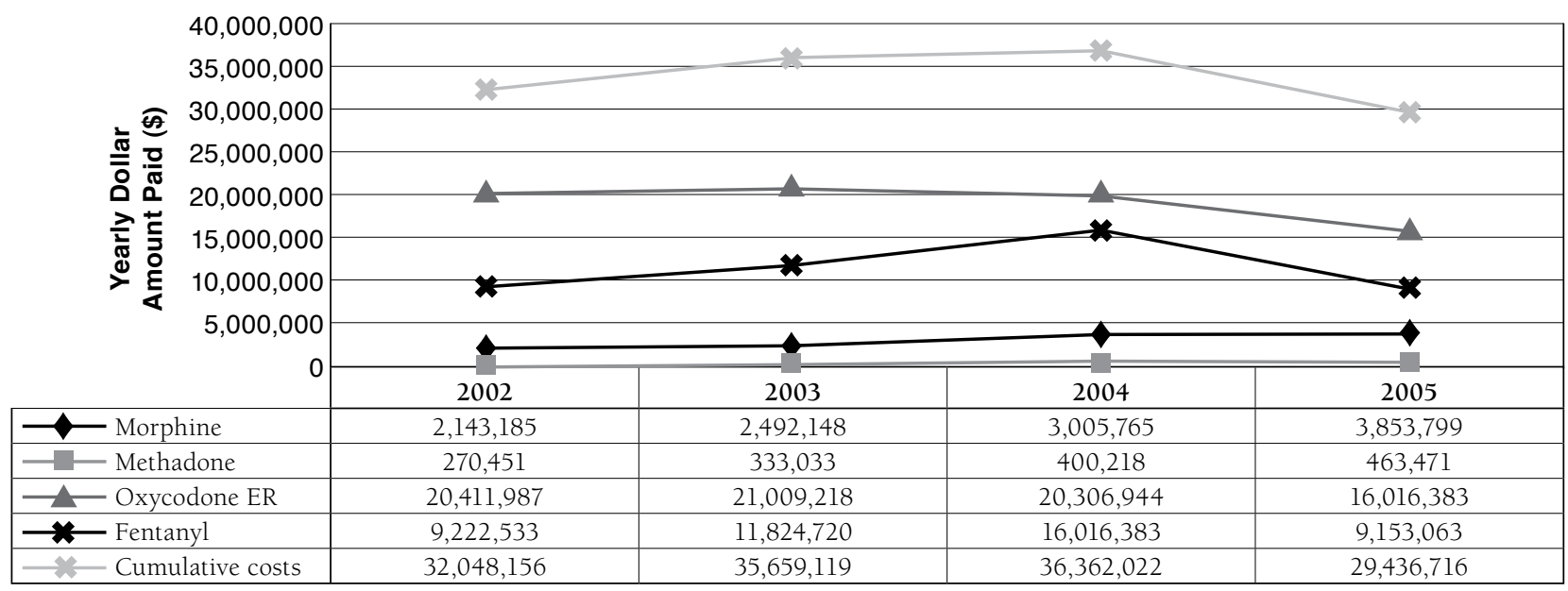

ER=extended-release.

\section{Discussion}

There is a limited amount of published literature covering the impact of prescription opioid oversight and management despite the well-documented risks associated with the increasing utilization of this medication class. The Medicaid PA policies for many medication classes have been shown to decrease the use of targeted drugs by $15 \%-92 \%{ }^{26-29}$ However, previously published articles have reported that the PA policies in most states have had relatively minimal effect in decreasing the utilization of opioid medications. ${ }^{31}$

Our study successfully demonstrated that a state Medicaid program initiative can result in a significant overall decrease in utilization, specifically for the targeted, more costly opioids. A number of management strategies were implemented during this initiative. These strategies included determining medical necessity, requiring step therapy through less costly alternatives, and implementing PA high-dose limits.

Defining a ceiling dose for opioids management can be difficult. The American Pain Society recognizes there is no defined high dose for morphine; however, a panel consensus has recently agreed that a reasonable definition is $>200 \mathrm{mg} /$ day (or equivalent). ${ }^{6,10}$ The Massachusetts Medicaid program was able to develop a customized strategy using utilization trends to set parameters influenced by and applicable to the state Medicaid population.

The total number of MassHealth members that filled at least 1 claim for an LAOA decreased by 17.8\% from 2002 to 2005 . This result is in contrast to a previous report that the PA process had not exhibited a significant impact on the utilization of opioid medications. Our study has shown that certain policies are able to influence the overall trends in opioid utilization. Our study was able to have an effect on the overall practice of prescribing high-dose opioid medications. By implementing highdose definitions, monitoring PA utilization, and proactively intervening by reaching out to prescribers to address appropriate use of opioid treatment regimens, we were able to produce an impact on the overall utilization of LAOA medications. 
It is important to note that the higher average daily dose of oxycodone ER and fentanyl transdermal system observed during the analysis may be partially explained by the requirement of a morphine ER or methadone trial prior to approval of both of these agents. Since doses are increased to pain relief or response when possible, when members are approved for oxycodone ER or fentanyl transdermal system, their average daily doses are expected to have already been escalated to accommodate the required primary trial of morphine ER utilization. This will have the effect of increasing the doses of the requested oxycodone ER and fentanyl transdermal system regimens. Any changes in trends may have also been masked by the difficulty in dose conversion calculations. ${ }^{33-35}$

When overall opioid costs were examined, there was a steady increase until 2004. After this point, there was a significant reversal of the trend toward lower cost. This coincided with a downward trend in cost noted for both oxycodone ER and fentanyl transdermal system. We have concluded that this trend is in direct relation to the new start PA policy for these medications. The introduction of generic formulations during this time period did not influence these results as indicated by the consistent average cost per claim noted in Table 2 .

Contrary to previous reports, this study shows that policy has the ability to affect the utilization of opioids. Furthermore, we implemented an initiative that was guided by clinical approval criteria set forth in the approach to appropriate pain management. This initiative was able to incorporate the likely need for dose increase due to inherent tolerance of this class of medications while properly balancing with the growing need to address potential misuse and abuse of opioid medications.

\section{Limitations}

When evaluating for potential limitations of our study, it is noted that a morphine equipotent ratio is used to determine or calculate the oral morphine equivalent doses. These ratios are not universally agreed upon, and there are differing ratios found in the literature. ${ }^{33-36}$ Another limitation could be the time frame between the implementation of changes and evaluation of outcomes when it comes to cost benefit. The overall cost of LAOAs decreased during the study period of 2002 to 2005, which correlated with an overall plan PMPM cost decrease of $6.3 \%$. However, there was an increase (albeit smaller) of 3.1\% PMPM increase in the opioid utilizer cohort. This could be explained by the fact that opioid utilizers at the second time point had demonstrated a need for more intense and more specific opiate selection for treatment. Specifically, chronic pain therapy typically requires increasing doses due to analgesic tolerance, and switching opiate therapy is a method of treating opiate tolerance.

\section{Conclusions}

The importance of the initiative studied here has recently been highlighted by a call for changes in opioid prescribing practices in response to a perceived epidemic of prescription drug abuse. ${ }^{37}$ When the PA process to monitor utilization was initially implemented, there were limited guidelines on the appropriate utilization of these agents. The American Society of Interventional Pain Physicians recently released updated guidelines for responsible opioid prescribing in chronic noncancer pain. ${ }^{38}$ This updated guideline provides increasing evidencebased support for the interventions that we have described in this study. Our study demonstrated that a state Medicaid program initiative can be successfully implemented to address the need of increased monitoring and management of LAOAs.

\section{Authors}

MARIA M. GARCIA, MD, MPH, is Associate Professor, Department of Medicine, University of Massachusetts Medical School, Worcester, Massachusetts, and Medical Director, Clinical Pharmacy Services, Commonwealth Medicine, University of Massachusetts Medical School, Shrewsbury, Massachusetts; MICHAEL C. ANGELINI, MA, PharmD, BCPP, is Psychopharmacology Consultant, Clinical Pharmacy Services, Commonwealth Medicine, University of Massachusetts Medical School, Shrewsbury, Massachusetts, and Associate Professor, Massachusetts College of Pharmacy and Health Sciences University, Boston, Massachusetts; and TARA THOMAS, RPH, MBA, BCPS, is Clinical Consultant Pharmacist, Clinical Pharmacy Services, Commonwealth Medicine, University of Massachusetts Medical School, Shrewsbury, Massachusetts. KIMBERLY LENZ, PharmD, is Clinical Pharmacy Manager, MassHealth, Quincy, Massachusetts, and Clinical Pharmacy Manager, Office of Clinical Affairs, University of Massachusetts Medical School, Shrewsbury, Massachusetts, and PAUL JEFFREY, PharmD, is Pharmacy Director, MassHealth, Quincy, Massachusetts, and Pharmacy Director, Office of Clinical Affairs, University of Massachusetts, Shrewsbury, Massachusetts.

AUTHOR CORRESPONDENCE: Maria M. Garcia, MD, MPH, University of Massachusetts Medical School, Department of Medicine, 55 Lake Ave., N., Worcester, MA 01655. Tel.: 508.856.5484; Fax: 774.442.6781; E-mail: maria.garciamd@umassmed.edu.

\section{DISCLOSURES}

The authors report no financial or other conflicts of interest. Concept and design of this study were contributed by Jeffrey, Garcia, Angelini, and Lenz. Data were collected by Thomas and Lenz and interpreted by Thomas, Lenz, Garcia, and Angelini. Garcia, Angelini, and Jeffrey wrote the manuscript with assistance from Thomas and Lenz, and the manuscript was revised by Angelini, Jeffery, and Garcia, with the help of Thomas and Lenz.

\section{ACKNOWLEDGMENTS}

The authors wish to thank Rose P. Mauro, Research Coordinator, for help with data and statistical analysis and Jorge Yarzebski, MD, MPH, Research Associate Professor, University of Massachusetts Medical School, for helpful comments and discussion and for work with manuscript revision. 


\section{REFERENCES}

1. Katz NP, Adams EH, Benneyan JC, et al. Foundations of opioid risk management. Clin J Pain. 2007;23(2):103-18

2. Boudreau D, Von Korff M, Rutter CM, et al. Trends in de-facto long-term opioid therapy for chronic non-cancer pain. Pharmacoepidemiol Drug Saf. 2009;18(12):1166-75

3. Caudill-Slosberg MA, Schwartz LM, Woloshin S. Office visits and analgesic prescriptions for musculoskeletal pain in U.S.: 1980 vs. 2000. Pain. 2004;109(30):514-19

4. Braden JB, Fan MY, Edlund MJ, Martin BC, DeVries A, Sullivan MD. Trends in use of opioids by noncancer pain type 2000-2005 among Arkansas Medicaid and HealthCare enrollees: results from the TROUP study. J Pain. 2008;9(11):1026-35.

5. Zerzan JT, Morden NE, Soumerai S, et al. Trends and geographic variation of opiate medication use in state Medicaid fee-for-service programs, 1996 to 2002. Med Care. 2006:44(11):1005-10

6. American Pain Society Quality of Care Committee. Quality improvement guidelines for the treatment of acute pain and cancer pain. JAMA. 1995;274(23):1874-80

7. Phillips DM. JCAHO pain management standards are unveiled. Joint Commission on Accreditation of Healthcare Organizations. JAMA. 2000;284(4):428-29

8. Okie, S. A flood of opioids, a rising tide of deaths. New Engl J Med. 2010;363(21):1981-85.

9. Gilson AM, Ryan KM, Joranson DE, Dahl JL. A reassessment of trends in the medical use and abuse of opioid analgesics and implications for diversion control: 1997-2002. J Pain Symptom Manage. 2004;28(2):176-88

10. Chou R, Fanciullo G, Fine P, et al. Clinical guidelines for the use of chronic opioid therapy in chronic noncancer pain. J Pain. 2009;10(2):113-30

11. Office of National Drug Control Policy. Prescription drug abuse. Available at: http://www.whitehouse.gov/ondcp/prescription-drug-abuse. Accessed February 5, 2014.

12. Federation of State Medical Boards of the United States, Inc. Model policy for the use of controlled substances for the treatment of pain. May 2004 Available at: http://www.fsmb.org/pdf/2004_grpol_Controlled_Substances. pdf. Accessed February 5, 2014

13. American Academy of Pain Medicine. Washington State Agency Medical Directors Group (AMDG) published guidelines on opioid dosing for chronic non cancer pain. October 2007. Available at: http://www.painmed.org/files/washington-state-amdg-opioid-guidelines-statement.pdf. Accessed February 5, 2014

14. Dunn KM, Saunders KW, Rutter CM, et al. Opioid prescriptions for chronic pain and overdose: a cohort study. Ann Internal Med. 2010;152(2):85-92

15. Centers for Disease Control and Prevention. Emergency department visits involving nonmedical use of selected prescription drugs-United States, 2004-2008. MMWR Morb Mortal Wkly Rep. 2010;59(23):705-09.

16. Substance Abuse and Mental Health Services Administration. Center for Behavioral Health Statistics and Quality. Highlights of the 2010 Drug Abuse Warning Network (DAWN) findings on drug-related emergency department visits. The DAWN Report. July 2, 2012. Rockville, MD. Available at: http:// samhsa.gov/data/2k12/DAWN096/SR096EDHighlights2010.htm. Accessed February 5, 2014

17. Center for Disease Control and Prevention. Unintentional drug poisoning in the United States. July 2010. Available at: http://www.cdc.gov/homeandrecreationalsafety/pdf/poison-issue-brief.pdf. Accessed February 5, 2014

18. Substance Abuse and Mental Health Services Administration. Center for Behavioral Health Statistics and Quality. Results from the 2010 National Survey on Drug Use and Health: summary of national findings. NSDUH Series.H-41, HHS Publication No. SMA 11-4658). 2011. Rockville, MD. Available at: http://www.samhsa.gov/data/nsduh/2k10nsduh/2k10results. htm. Accessed February 5, 2014.

19. Manchikanti L, Fellows B, Ailinani H, Pampati V. Therapeutic use, abuse, and non-medical use of opioids: a ten-year perspective. Pain Physician. 2010;13(5):401-35
20. Birnbaum HG, White AG, Schiller M, Waldman T, Cleveland JM, Roland CL. Societal cost of prescription opioid abuse, dependence and misuse in the United States. Pain Med. 2011;12(4):657-67.

21. White AG, Birnbaum HG, Mareva MN, et al. Direct costs of opioid abuse in an insured population in the United States. J Manag Care Pharm. 2005;11(6):469-79. Available at: http://www.amcp.org/WorkArea/ DownloadAsset.aspx?id=7223

22. Executive Office of the President of the United States, Epidemic responding to America's prescription drug abuse crisis. 2011. Available at: http://www.whitehouse.gov/sites/default/files/ondcp/issues-content/prescription-drugs/rx_abuse_plan.pdf. Accessed February 5, 2014.

23. The Massachusetts OxyContin and Other Drug Abuse Commission. Final report. 2009. Available at: http://www.ok.gov/odmhsas/documents/ MA\%20RX.pdf. Accessed February 5, 2014

24. Bagchi A, Verdier J, Esposit D. Chartbook: Medicaid pharmacy benefit use and reimbursement in 2005. Mathematica Policy Research. Prepared for the Centers for Medicare \& Medicaid Services. June 2009. Available at: http://www.mathematica-mpr.com/Publications/PDFs/health/chartbook2005.pdf. Accessed February 5, 2014.

25. U.S. Department of Health and Human Services. Substance Abuse and Mental Health Services Administration. Office of Applied Studies. State estimates of substance use and mental health from the 2005-2006 National Surveys on Drug Use and Health. Available at: http://oas.samhsa. gov/2k6state/adultTabs.htm. Accessed February 5, 2014.

26. Fischer MA, Schneeweiss S. Avorn J, Solomon DH. Medicaid priorauthorization programs and the use of cyclooxygenase-2 inhibitors. New Engl J Med. 2004;351(21):2187-94.

27. Smalley WE, Griffin MR, Fought RL, Sullivan BS, Ray WA. Effect of a prior-authorization requirement on the use of nonsteroidal anti-inflammatory drugs by Medicaid patients. New Engl J Med. 1995;332(24):1612-17.

28. Delate T, Mager DE, Sheth J, Motheral BR. Clinical and financial outcomes associated with a proton pump inhibitor prior-authorization program in a Medicaid population. Am J Manag Care. 2005;11(1):29-36.

29. Roughead EE, Zhang F, Ross-Degnan D, Soumerai S. Differential effect of early or late implementation of prior authorization policies on the use of Cox II inhibitors. Med Care. 2006;44(4):378-82

30. Morden NE, Sullivan SD. States' control of prescription drug spending: a heterogeneous approach. Health Aff (Millwood). 2005;24(4):1032-38.

31. Morden NE, Zerzan JT, Rue TC, et al. Medicaid prior authorization and controlled-release oxycodone. Med Care. 2008;46(6):573-80.

32. Svendsen K, Borchgrevink PC, Fredheim O, Hamunen K, Melbye A, Dale O. Choosing the unit of measurement counts: the use of oral morphine equivalents in studies of opioid consumption is a useful addition to defined daily doses. Palliat Med. 2011;25(7):725-32.

33. OxyContin (oxycodone hydrochloride controlled-release) tablets. Purdue Pharma L.P. 2013. Available at: http://app.purduepharma.com/xmlpublishing/pi.aspx?id=o. Accessed February 5, 2014.

34. Pereira J, Lawlor P, Vigano A, Dorgan M, Bruera E. Equianalgesic dose ratios for opioids: a critical review and proposals for long-term dosing. J Pain Symptom Manage. 2001;22(2):672-87.

35. Duragesic (fentanyl transdermal system). Ortho-McNeil-Janssen Pharmaceuticals, Inc. 2013. Available at: http://www.duragesic.com/prescribing-information.html. Accessed February 5, 2014.

36. Walker PW, Palla S, Pei BL, et al. Switching from methadone to a different opioid: what is the equianalgesic dose ratio? J Palliat Med. 2008;11(8):1103-08.

37. Alexander GC, Kruszewski SP, Webster DW. Rethinking opioid prescribing to protect patient safety and public health. JAMA. 2012;308(18):1865-66

38. Manchikanti L, Abdi S, Atluri S, et al. American Society of Interventional Pain Physicians (ASIPP) guidelines for responsible opioid prescribing in chronic non-cancer pain: part 2-guidance. Pain Physician. 2012;15(3 Suppl):S67-S116. 